\title{
ESTIMATING ODOR IMPACT WITH COMPUTATIONAL FLUID DYNAMICS
}

\author{
Michael Ruby and J.D. McAlpine \\ Envirometrics, Inc. \\ 4803 Fremont Ave N \\ Seattle WA 98103
}

\begin{abstract}
The detection and nuisance concentrations of odors are frequently quoted in terms of dilutions from the initial source concentration. Meteorological dispersion modeling has been used to estimate the dilutions achieved between a release point, such as a stack, and a downwind receptor. Conventional models have proven to yield reasonable results for neutral and stable atmospheric conditions, within the acknowledged limitations of Gaussian dispersion models. However in regions with numerous buildings or sharp topography-induced turbulence, the Gaussian models are not able to provide results which take the turbulence into account. Computational Fluid Dynamics (CFD) is becoming available as a tool to assist with modeling the airflow and dispersion of pollutants among complex urban geometries on the scales of a section of a building exterior up to a few city blocks. This tool allows more accurate predictions of impacts within the regions of local turbulence. This can be especially important in urban areas where several buildings are within a mutual zone of influence and where air intakes are located on the top of a building with its own recirculation zone.
\end{abstract}

This paper illustrates the capabilities of CFD in modeling odor dispersion in urban microenvironments and compares the results of CFD modeling in actual source-neighbor building situations with results obtained using the conventional U.S. EPA model ISCST3 and the newer U.S. EPA model AERMOD in complex terrain modes.

A scaling factor has been frequently used to estimate the higher, short-term response to odors when using the 20 to 30-minute average dispersion coefficients of the conventional U.S. EPA models. CFD models report a steady state solution and the results also need to be adjusted to reflect the short-term odor response. This paper summarizes a peak-tomean adjustment that is appropriate to CFD models that has been developed using an extensive data base collected by the U.S. EPA during its analysis of the proposal for onehour ambient sulfur dioxide standards.

\section{KEYWORDS}

Model, modeling, odor, concentration, dilutions, meteorological, dispersion, Gaussian, ISC, AERMOD, PRIME, urban, building, computational, fluid, dynamics, CFD, CFD2000, K-e, turbulence, peak-to-mean, time scale 


\section{INTRODUCTION}

Commonly in today's dense urban landscapes, manufacturing, food preparation, landfills, and other sources of strong odor are moving closer to residential neighborhoods and offices. Recurring exposures to nuisance odor may increase stress at the workplace or adversely affect the quality of life at home. Therefore, it will be beneficial to have a forecast of possible odor impact when a new source or new receptor is being considered, so changes can be made during construction when more options are available. If odor impacts are evident from an existing source or at an existing receptor, a tool is needed to analyze the change in impact with alternative arrangements for the source or air intakes. In both of these cases, air dispersion modeling is an important tool to gauge odor impacts at alternative receptor or source conditions.

Today, the air dispersion model most frequently used for regulatory purposes is version 3 of the U.S. EPA model "Industrial Source Complex - Short Term" (ISCST3). The next generation, and recently adopted, model is the AMS/EPA Regulatory Model (AERMOD), which contains a more elegant method for generating and using meteorological variables. Each of these models is a steady state, analog dispersion model primarily validated for near-field analysis. For far-field modeling, CALPUFF is the regulatory model of choice. Although it has many advantages for odor modeling, CALPUFF is not easily applicable to the space and time scale of interest in urban odor modeling.

ISCST3 and AERMOD may also be useful tools for odor impact forecasting for larger sources in landscapes fairly devoid of buildings other than the source building or building group. However, neither model is designed to handle the interaction of the wind field with buildings downwind of the source building group. Further, some small sources, such as kitchen or lab exhaust stacks, may only become a nuisance in a very small space scale, when adjacent to building air intakes or windows or near neighboring buildings. Neither model was intended to handle the specifics of wind flows around the details of buildings.

In contrast, Computational Fluid Dynamics (CFD) is precisely appropriate for modeling these smaller scales, where the interaction of wind with the building elements and nearby buildings is important in determining the path of the odor plume. CFD can be used to directly compute the steady state wind-flow around buildings and over topography. Recirculation zones, wind jets, turbulence, and buoyancy can all be taken into account to model the plume stream and compute concentrations at nearby receptors.

In this paper, two sample projects are discussed. The first illustrates modeling dispersion of an odorous kitchen exhaust around a set of buildings to allow design decisions to prevent future impacts at several air intakes on another building. This example demonstrates why ISCST3 or AERMOD would not be useful tools for small-scale odor impact analysis. The second illustrates a larger scale, comparing the modeling results using three different models: a CFD model, ISCST3 and AERMOD. The strengths and weaknesses of each model are discussed. 


\section{PHYSICAL THEORY UNDERLYING CFD, ISCST3, AND AERMOD}

\section{Computational Fluid Dynamics}

CFD modeling basically solves the fundamental physical equations of conservation of mass, momentum and energy for a fluid, in this case air, moving through a space that has been subdivided into small, fixed geometric volumes. This generates five equations (the continuity equation, the conservation of momentum equation in three dimensions, and the energy equation) which are expressed with seven unknown variables (pressure, density, temperature, internal energy and three direction components of velocity), called the Navier-Stokes equations. Such a system of equations is not directly solvable without additional assumptions that can generate additional equations leading to an equal number of equations and unknown variables. The easiest assumption to make is that the fluid is a perfect gas, which is reasonable for air at the surface, although the gravitational pressure gradient in the real atmosphere limits the range of validity of this assumption.

The most useful solutions to these dynamic equations are the equilibrium solutions averaged over space and time. To find the steady state solution, Reynolds (or "ensemble") averaging is applied to the equations. That is, the equations are solved for the mean of $u(t)=u(t)=$ mean $\left(u+u^{\prime}(t)\right)$. When this statement of the time varying velocity is substituted into the equations, vector cross product terms are generated, which are known as the Reynold's stresses. The averaged resulting equations are called the Reynolds averaged Navier-Stokes (RANS) equations. Turbulence modeling is the accounting for these stresses and their dissipation throughout the model space. The much used $\mathrm{K}-\varepsilon$ turbulence model makes the additional assumption that the dissipation rate is the same in all directions in free space, which is reasonably accurate for lower velocity, but turbulent, winds in the atmospheric boundary layer.

CFD modeling then proceeds by finding a numerical solution to this set of equations for each small geometric volume in the model and matching the solutions at each face of each volume. Finding a scheme for making these calculations and matching up the results at each face in such a way that the iterative trial and error calculation quickly converges to a stable (that is, less than a specified small change with each successive iteration) and approximately consistent answer throughout the entire space was the mathematical breakthrough that allowed CFD modeling.

The solutions can be solved in parallel for different species in the same space so the dispersion of one species, such as a pollutant released at a point, can be mapped as it mixes and is transported downwind by the main transport wind and crosswind by the turbulent eddies. The CFD model then represents a steady state solution of the average wind field over a period of time with certain atmospheric conditions. However, physical airflow at this scale is highly variable, and never in steady state. True dispersion of the plume would be quite chaotic, with sections of the plume potentially quite a lateral distance from the average plume centerline at any one time. In the Gaussian dispersion models, the solution represents the average concentration over time at locations along and perpendicular to the plume centerline, as determined by the field studies that were used to 
create the dispersion coefficients. The results reflect the averaging period of the experiments, which ranged upward of 20 to 30 minutes. With CFD models we generate the concentrations perpendicular to the transport direction by turbulent eddies, with sizes that derive from the constants we choose for the models. Thus, neither approach is capable of providing an instantaneous snapshot of the dispersing plume.

CFD modeling is essentially a computerized wind tunnel. In the past, large mainframe computers were required to compute CFD problems. With the advent of fast, powerful desktop computing, the ability to model complex computational fluid dynamic problems in economical timeframes has increasingly become a reality. Now, using an efficient commercial CFD package, a problem can be solved in a matter of hours on a desktop computer. We have found that a computer with 1Gbyte of memory and operating at 2 $\mathrm{GHz}$ on a single processor is adequate to provide runs in a reasonable time (often from minutes to a few hours but up to overnight for very complex models).

Many commercial CFD packages are now available that offer a variety of features, but the main aspects of the CFD approach is similar for most packages. First, a package has a geometry creation and visualization program where the CFD problem is set up. The project geometry and mesh, including buildings, topography, vegetation, and boundary conditions such as air inlets, outlets, and exhaust stack parameters, are all established in this first program. The mesh defines the boundaries of the free space in which air transport occurs but also defines the small computation volumes in that free space. When the model parameters are all defined, the CFD project is sent to a second program, the solver. In the solver, the equations of fluid motion are solved for the given geometry by walking the solution across all the computation volumes and slowly forward in time, to allow the turbulent eddies and other features of the flow field to develop and reach equilibrium. Since the steady state solutions to the equations of motion are parametric, this time-marching technique, given adequate initial conditions, can reach a steady state solution. Finally, the solution is loaded into a visualization program, where flow field streamlines, local velocity vectors, scalars, such as species concentration or temperature, and a variety of other features can be graphed to observe the results.

The commercial CFD package we are using is CFD2000 by Adaptive Research, which is equipped with the fast, efficient STORM solver. This program provides the classical firstorder closure scheme, several turbulence models to account for steady state turbulence and advanced numerical schemes to solve CFD problems efficiently. Several types of K$\varepsilon$ turbulence models are available to use with the solver including a Re-normalized Group (RNG) model, and Chen-Kim model. Some other packages provide additional models but current reports do not suggest their results are significantly different for these types of projects. The Large Scale Eddy model holds promise as a useful model but at this time the algorithms require more computational power than the current desktop computers can provide in a reasonable time. 


\section{ISCST3 PRIME}

Unlike CFD, ISCST3 does not compute the wind fields and then transport the released pollutant progressively through the field. ISCST3 relies on a single point observation of the winds and assumes this one direction and wind speed is valid for all locations in the domain for the specified observation hour. The wind speed along the plume centerline, however, is varied with the height of the plume centerline above the terrain, using different values for a power function factor for unstable, neutral and stable atmospheric conditions. It then changes the wind speed and drection at all locations for the next hour to that observed and calculates values for that following hour. This is considered a valid approach since modeling over many hours yields an average value which has been found to correspond reasonably well with the observed average values downwind or with a maximum hourly value that may not be actually observed during the hour of the calculated maximum but corresponds reasonably well with the maximum observed value.

The pollutant is assumed to be released at the source and then transported instantly to all receptors. The concentration decreases with the distance along the downwind plume centerline from the source and horizontally and vertically from the plume centerline as determined by the dispersion coefficients, which differ for unstable, neutral and stable conditions and urban or rural surface roughness.

If an election is made to consider terrain in the ISCST3 calculations, terrain that rises as you move away from the release point is accounted for by either assuming it is not there at all or by floating the plume up with the terrain. In the first case, the receptor elevations are raised to their own height above the terrain plus the height of the terrain but the plume remains at its final plume rise elevation, resulting in the receptors being located closer to the more concentrated center of the plume ("flagpole receptors"). In the second case, the centerline of the plume is moved up, following the terrain up until the terrain is the same height as the release elevation of the stack. For receptors that are higher than the final plume height before the terrain, the plume remains at its original elevation for stable atmospheres but is moved up further, at half the rate of actual rise of the terrain for unstable and neutral atmospheres but always at least 10 meters above the terrain. For receptors above the final plume rise elevation, the horizontal spread of the plume is assumed to be uniform over a $22.5^{\circ}$ sector. Thus for these receptors the downwind distance is the direct distance between the source and receptor without consideration of the crosswind distance. For receptors of height intermediate between the release height and the final plume rise elevation, calculations are made following both schemes and the highest concentration is used.

Concentration calculations in the immediate vicinity and downwind of buildings, a location where odor calculations are often required, are computed using separate building downwash algorithms. The PRIME downwash model has been recently introduced as an addition to both the ISCST3 and AERMOD models and a replacement for earlier, simpler downwash models. It is semi-empirical, being based on detailed field studies and wind tunnel measurements to set the values of some of the constants as well as numerical solutions of the Navier-Stokes equations. 
PRIME calculates the height and length of the cavity above the roof and the length and horizontal extent of the cavity behind the building from the building dimensions and the wind direction with respect to the building. The slopes of the streamlines of air movement approaching, over and behind the building are then calculated using information about the building dimensions and the wind direction. The calculations of the plume path near the building determine if the plume will be captured entirely or partially in the rooftop cavity or the cavity behind the building. If it is, the pollutants in the cavity are assumed to be well mixed within the cavity and are modeled downwind as a volume source the size of the cavity. The pollutants that are not captured by the cavity are modeled downwind as a virtual point source and the two sources are added together.

Downwind of the building both the horizontal and vertical dispersion coefficients are increased by the enhanced turbulence intensity in the cavities and the building wake. When the turbulent intensity in the wake has decayed to ambient levels, a virtual source distance is estimated by PRIME to transition to the standard ISCST3 formulation and dispersion coefficients.

PRIME can be used with more than one building close to the source stacks but cannot be used to compute the plume path through or affected by the building cavities for another building or group of buildings at a distance downwind from the initial industrial source complex.

\section{AERMOD}

Like ISCST3, AERMOD assumes that the windfield is uniform throughout the modeling domain for each hour and transports the pollutant instantly to all receptors, changing all again the following hour. AERMOD has stayed close to the data requirements and external interface of ISCST3 in order to ease the transition of the user community, but this is where the similarity ends. AERMOD provides a much more detailed characterization of the atmospheric conditions at the location of the source and each receptor, yielding potentially different values for the concentrations from that calculated by ISCST3. That the predicted concentrations are quite similar in many cases is testimony to the substantial skills of those who conducted the experiments that generated the empirical stability classification scheme and the empirical dispersion coefficients used in ISCST3.

AERMOD differs from ISCST3 in its development of atmospheric stability information from the meteorological data, in the resulting dispersion coefficients and vertical profiles of wind, temperature and turbulence, in its plume rise calculations, in its treatment of both the convective (unstable) boundary layer and the stable boundary layer, and in its characterization of and treatment of terrain.

AERMOD is based on similarity scaling of the surface boundary layer of the atmosphere, somewhat like the use of Reynolds numbers to characterize laminar and turbulent flow in fluids. This approach builds from an understanding of the importance of the energy 
balance in the lower atmosphere and the surface roughness, which generates mechanical turbulence as wind blows across the surface. The energy balance is calculated from the hourly solar elevation angle, surface temperature, and cloud cover and the seasonal albedo (that is, the surface reflectivity) and soil moisture or from a direct measurement of the hourly net solar radiation. Estimates of soil moisture, surface roughness and albedo can be developed from local land use data. The computed sensible heat flux, most importantly if the flux is toward or away from the surface, then characterizes the atmospheric stability.

Because AERMOD can accept meteorological data from several elevations and not just the single point used by ISCST3, it uses interpolations of the actual meteorological data between any multiple levels available to it. Below the lowest level of measurements and above the highest level it uses similarity scaling of the variables to develop elevation specific values. If only one measurement level is available, AERMOD uses similarity scaling throughout the boundary layer.

Depending on the stability, AERMOD follows two different procedures for computing the basic information it needs to later scale the various meteorological variables and make calculations of dispersion coefficients. For convective conditions AERMOD first computes the surface friction velocity and the Monin-Obukhov length from the energy balance results and the measured surface wind speed. Next it computes a convective velocity scale and temperature scale from the energy balance results and the measured early morning temperature sounding for that day. For stable conditions AERMOD uses the measured wind speed and the cloud cover or a two level temperature measurement to calculate the sensible heat flux, temperature scale, surface friction velocity and MoninObukhov length.

The surface friction velocity is used to scale the wind speed with elevation, although AERMOD uses different computation procedures for the convective and stable layers. The wind direction is not changed with elevation unless multiple level measurements show a rotation. In a convective layer the temperature is assumed to be constant above a thin surface layer while in a stable layer AERMOD calculates the temperature gradient at each elevation from the temperature scale and the Monin-Obukhov length.

In the stable boundary layer both the vertical dispersion coefficient and the horizontal dispersion coefficient are taken as entirely due to mechanical turbulence and are calculated from the surface friction velocity, although through a different formulation for the vertical and horizontal values. In the convective boundary layer both coefficients are the sum of the mechanical turbulence value used with the stable boundary layer and a value computed using the convective velocity scale, again with a different formulation for the horizontal and vertical coefficient. Each dispersion coefficient is scaled with height above the surface. The resulting concentration distributions are Gaussian in a stable layer and in the horizontal in a convective layer. The probability distribution function is bi-Gaussian in the vertical in a convective layer. AERMOD modifies the distributions to take into account the additional mixing in stable layers in urban areas due 
to heat generated near the surface even at night and the broadening of the plume due to plume meander.

Because AERMOD scales with elevation the values needed to compute concentrations, the computational domain has an inhomogeneous boundary layer. To simplify the calculations AERMOD calculates an "effective" average value for the wind speed, dispersion coefficients and temperature gradient over the region between the receptor height and the elevation of the mass centroid of the plume at that distance. For stable conditions the centroid is just the plume centerline along the final plume rise. For convective conditions the centroid can be above that centerline, requiring a more complex calculation of the average.

To treat rising terrain AERMOD computes for each receptor a terrain height scale. AERMOD then models plumes for two cases, receptors that are at a height equal to their own height plus the height of the terrain and receptors that are only at their own height. This effectively creates a plume that ignores the terrain and a plume that follows the terrain. AERMOD uses the terrain height scale, the height of the plume relative to the terrain, the degree of atmospheric stability and the wind speed to weight each of the two cases and then add them together to obtain the concentration estimate for the receptor. In stable conditions the plume that ignores the terrain is given the most weight while in neutral and unstable conditions the plume traveling over the terrain is dominant.

The PRIME downwash algorithms are implemented in AERMOD using the appropriate values calculated by AERMOD to drive the PRIME calculations of the dimensions of the recirculation and building cavities. However, similar to its terrain calculations, AERMOD makes calculations for two cases, one for a plume affected by building downwash and one for a plume that is not. The two cases are added up with a weighting factor that depends on the receptor location in the building wake. If the receptor is wholly within the wake region the downwash mode is used. As the receptor distance moves beyond the immediate wake region the weighting is increased for the plume not affected by the downwash until a point where the turbulent intensities have decayed to ambient levels and the downwash plume is no longer counted. A light wind correction factor avoids overpredictions of downwash effects at low wind speeds.

\section{ODORS AND DILUTIONS}

When modeling odors, the primary interest is in determining the approach of the released odor to a non-nuisance or non-detectable level at the receptor. This is most easily expressed as how many dilutions with clean ambient air the odor has experienced between the release point and the receptor. This can be modeled using a source set for 100 percent exhaust of the odor and then identifying the concentration isopleth corresponding to the desired dilution level. For example, at the concentration isopleth of 0.01 the odor will be diluted 100 times from the source concentration. 
Before the odor concentration can be calculated, a steady state wind field must first be modeled to establish the transport conditions. Next, the fully-evolved wind field is frozen and the odor is introduced into the field at the source. Scalar transport of the odor is time marched until a steady state of odor concentration is reached in the domain. Visualization tools allow display of the area within the outer limits of a plume at this concentration (or dilution) or as the concentrations along a viewing screen showing the isopleths or a color scale of concentration. Both visualization methods are shown in the projects illustrated in this paper.

\section{Time scaling of modeled odors}

The human response to odors is generally quite short term, on the order minutes or less. Steady state meteorological dispersion models provide results that are averaged over much longer periods. The dispersion coefficients used with ISCST3 were developed from experiments with an averaging time of approximately 20 to 30 minutes. No detailed evaluation has been made of the various experiments that have formed the basis for selection of the constants used in AERMOD or the CFD models but they can be assumed to be of a similar order.

Analysis of ambient data has found regular relations between the concentrations measured at shorter times and at longer times. For times of the order hours compared to times of order days or months the ratio is partially related to the placement of sources relative to the receptor and the emission characteristics of the particular type of local source. But for times of the order minutes compared to approximately one hour the ratio is controlled almost entirely by fluctuations in the windfield except for sites immediately adjacent to a rapidly varying source. Turner (1970) reviewed several studies that support a power law relation between the time periods of the short-term average value and the long-term average value and recommended a value between 0.17 and 0.2 for the exponent. For a conversion from a one-hour concentration to the equivalent 3-minute concentration he recommends a factor of 1.7. For conversion from a 20-minute value to the equivalent 3 -minute value the factor would be 1.4.

More recently the EPA has conducted studies (Thompson, 2000) of 5-minute and onehour ambient data to support a proposed one-hour ambient sulfur dioxide standard. The national monitoring network contains simultaneous 5-minute and longer average values for sulfur dioxide from 14 states for up to 11 years. There were more than 1 million data pairs in their data set. EPA developed ratios between the maximum 5-minute average value in an hour and the one-hour average value for the same hour at the same monitor. A cumulative probability plot of the ratios is given in Figure 1. Reanalyzing their data yields an average ratio for 5-minutes to one-hour of 1.38 with a standard deviation of 0.11 . This would suggest an exponent of 0.13 for the power law function. At plus one standard deviation the suggested exponent would be 0.16 while at minus one standard deviation the exponent suggested is 0.11 .

We have elected to use 1.4 as our correction factor for consistency with past practices. Because dilutions are the inverse of odors as they are presented, it would be necessary to 


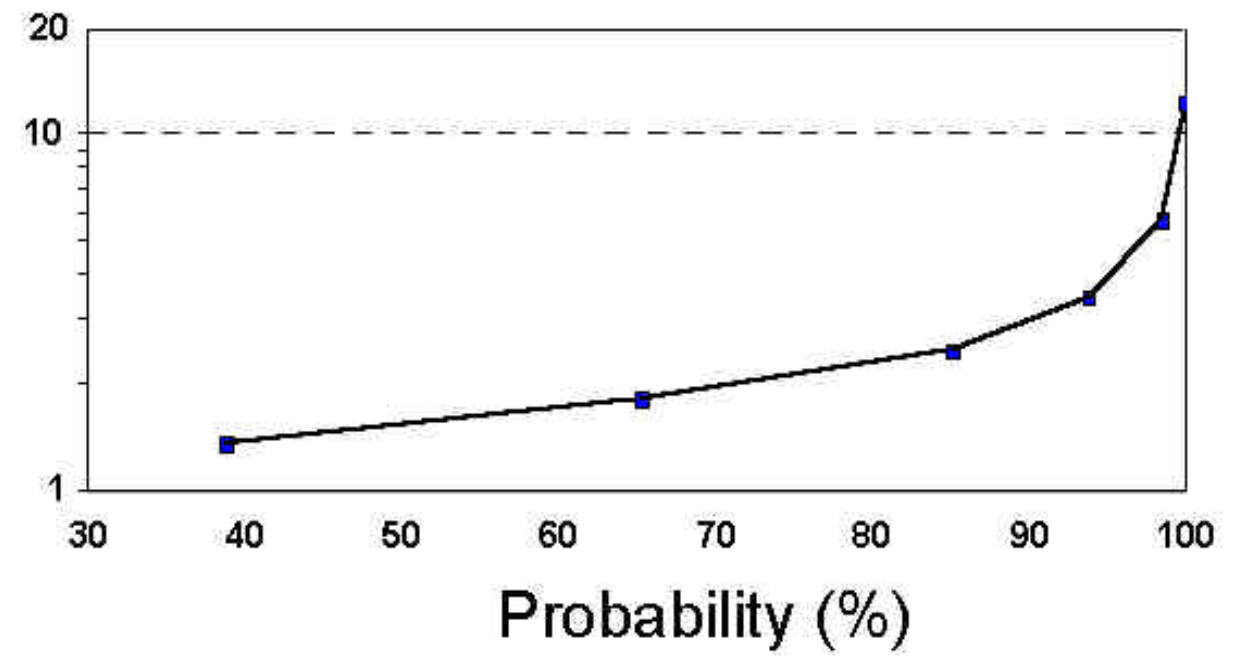

Figure 1. Cumulative probability distribution of ratios of 5-minute peak to 1-hour mean. (Source: Thompson, 2000)

display a CFD computed plume boundary or isopleth at 715 dilutions to properly display a short-term plume sensed as at 1000 dilutions.

\section{KITCHEN EXHAUST STACK CASE STUDY}

This project is an example of the power of CFD to analyze odor impact in local, urban scales. The interaction of airflow between two sets of adjacent buildings in this project determines the path of the plume, a path which is clearly not the straight-line transport assumed by the Gaussian models. Sensitive receptors exist on both sets of buildings and at different elevations. The objective of this project is to determine the best stack location and height to minimize any odors from kitchen stacks on one building at the sensitive receptors on the other buildings. These receptors are residences and offices with longterm occupants who will complain about repeated stack odors. The particular type of restaurant planned for the location is expected to be frying and releasing significant quantities of garlic and soy sauce odors. These odors have been observed to have a very low detection concentration and a high source strength.

The proposed restaurant kitchen exhaust stack was initially nestled among several air handling units with a height of 10 feet. The emissions might reach several sensitive receptors, as shown in Figure 2. First, are the air handling units on the building where the restaurant is located. Second, the dormers and every apartment in the two adjacent buildings have operable windows. Finally, there are also air handling units on the oof of the triangular building across the alley.

Unique airflow patterns will form as wind fields interact with the various buildings, especially the tower, and the gap between the two sets of buildings. Moderate winds from the north are common throughout the year. These winds could cause the plume to reach one or the other of the receptors during many hours of the year. 

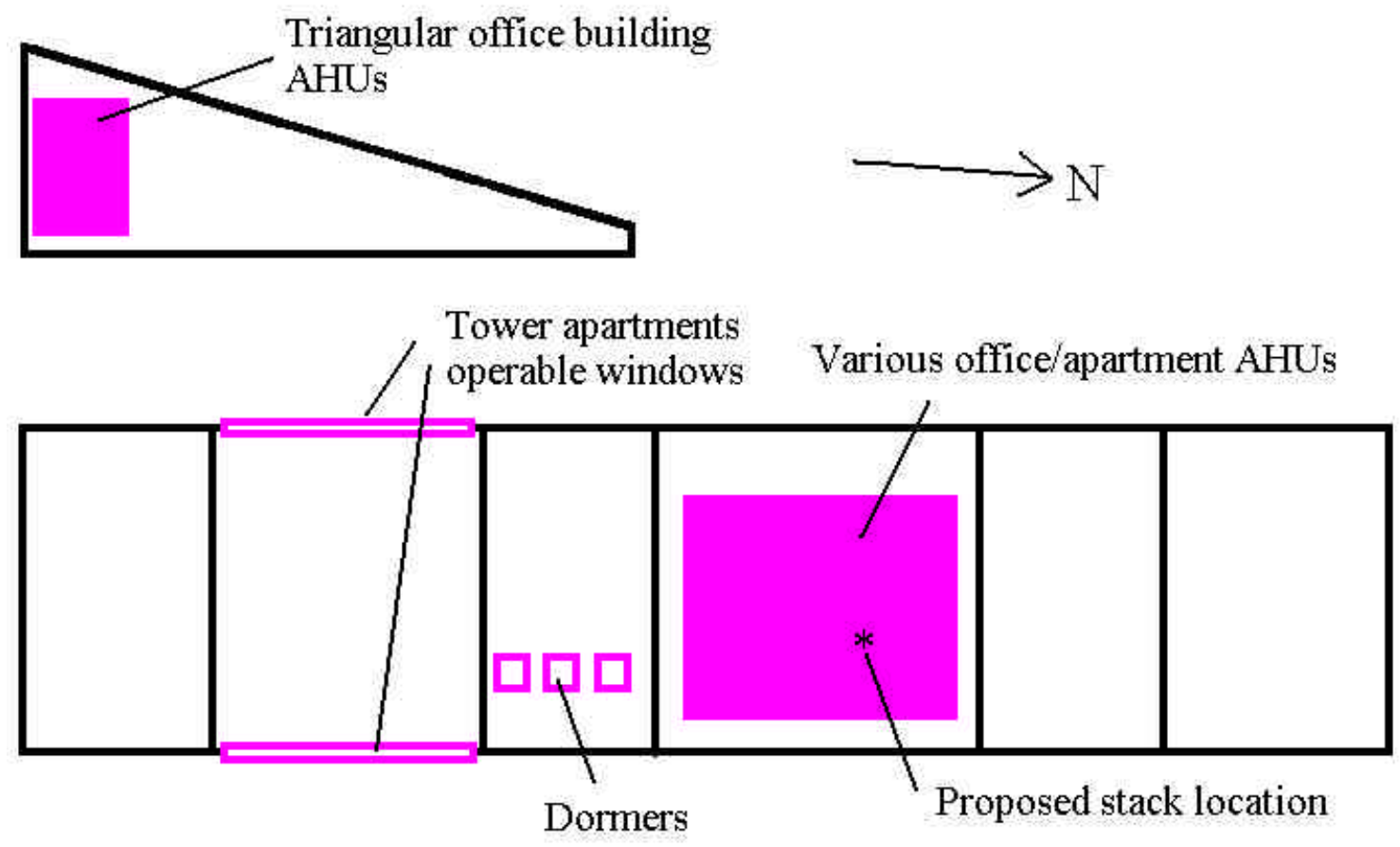

Figure 2: Illustration of the site domain. The main set of buildings include the proposed restaurant. Operable windows exist at several locations on the main building complex. The adjacent triangular building includes only offices with a main air intake at the roof and all sealed windows.

\section{Modeling}

Modeling was conducted using a variety of wind directions and speeds to analyze the impacts at the sensitive receptors. Although two wind directions would probably be adequate to analyze the impact during maximum conditions, enough modeling runs must be performed to analyze the variability of impacts. Therefore, in this case five different wind directions were chosen for modeling: a true north wind and $7.5^{\circ} \& 15^{\circ}$ east and west of true north. Wind speed was modeled at $2 \mathrm{~m} / \mathrm{s}, 4 \mathrm{~m} / \mathrm{s}$ and $8 \mathrm{~m} / \mathrm{s}(4.5 \mathrm{mph}, 9 \mathrm{mph}$, and $18 \mathrm{mph}$ ). These wind speeds represented the entire spectrum of observed speeds out of the north, with a $2 \mathrm{~m} / \mathrm{s}$ wind being the most common hourly averaged speed, $4 \mathrm{~m} / \mathrm{s}$ the most common high speed (occurring roughly 100 hours per year), and $8 \mathrm{~m} / \mathrm{s}$ representing the average gust during the stronger north wind hourly periods.

Modeling was conducted using the standard K- $\varepsilon$ model. Wind and pressure fields were solved and then frozen for introduction of the exhaust (the velocity fields at the stack are solved during the wind field run with just air at stack temperature coming out of the stack). The exhaust is dispersed throughout the field for an adequate length of time, varying depending on the initialized wind speed. Usually about one to two minutes of dispersion is adequate at achieving a steady state concentration of exhaust in this domain. 
Exhaust temperature will have a large effect on plume rise for larger exhaust stacks if the temperature of the exhaust is significantly above ambient temperature. However, for kitchen exhaust, the exhaust is usually only a few degrees warmer than ambient temperatures on warm summer days and the exhaust stack itself is fairly small. This means that buoyancy is insignificant for a good portion of the year. At the site of interest in this project, north winds primarily occur under summer conditions. Therefore, buoyancy was not taken into account in this study. In other studies, however, buoyancy would be very important to include in the modeling to ensure a proper plume path.

\section{Results}

The initial modeling assumed the proposed height of 10 feet for the kitchen exhaust stack. This proved to be nadequate as the adjacent air handling units were already 8 feet tall. During moderate to strong winds the plume reached the air handling units at no more than 50 dilutions for most wind directions.

Additional modeling runs with 20 foot stacks were tried to find a stack height that would avoid impacts at the adjacent air handling units. This height proved sufficient to avoid impacts at the adjacent units for all wind directions. However, the path of the plume during the common true north winds suggested another potential problem. As seen in Figure 3, the plume reaches the air intakes of the adjacent triangular office building, located in a mechanical penthouse at the far end of the south roof.

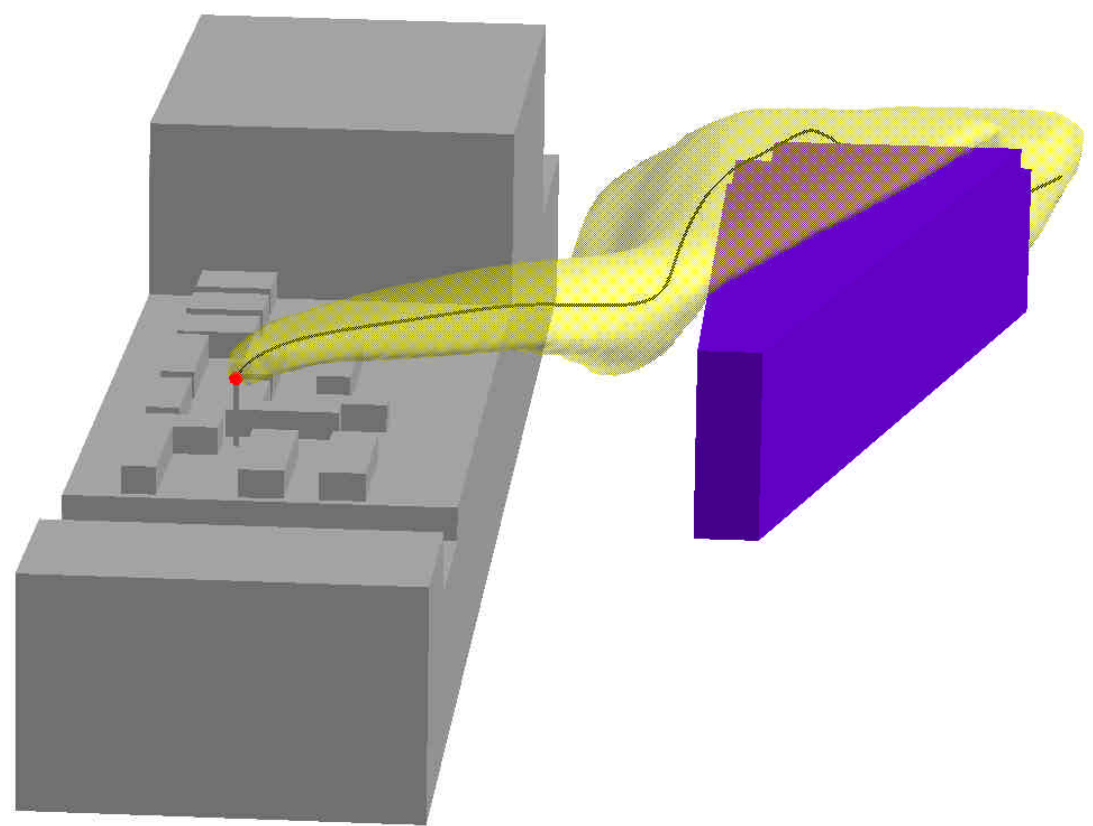

Figure 3: Kitchen exhaust plume from 20-ft stack reaching the adjacent office building air intakes. The plume centerline is illustrated as a black streamline. The plume boundary is at 1,000 dilutions. 
Though quite a distance downwind, the dilution levels at the office building air intakes remain relatively small because the plume remains coherent with neutral stability. As seen in Figure 4, the dilution levels are less than 1,000 dilutions-to-threshold (d/t). The average impact across both air intake grills is 500 dilutions. Note that the scale in the figure shows concentrations and is the inverse of dilutions.

Further modeling was carried out with a stack at 30 feet. Although rather tall, the stack proved successful at avoiding heavy impacts at the air intakes on either building. Some impacts are still possible at operable windows on the top story of the adjacent tower apartments during rare winds.

CFD provided the detail in building elements and microscale windflows to predict the concentration of odors at different locations around buildings or sets of buildings. The Gaussian models could not have supplied enough detail to find concentrations at different building elements. The CFD model can also be easily customized to attempt different alternatives such as higher stacks and different building geometries.

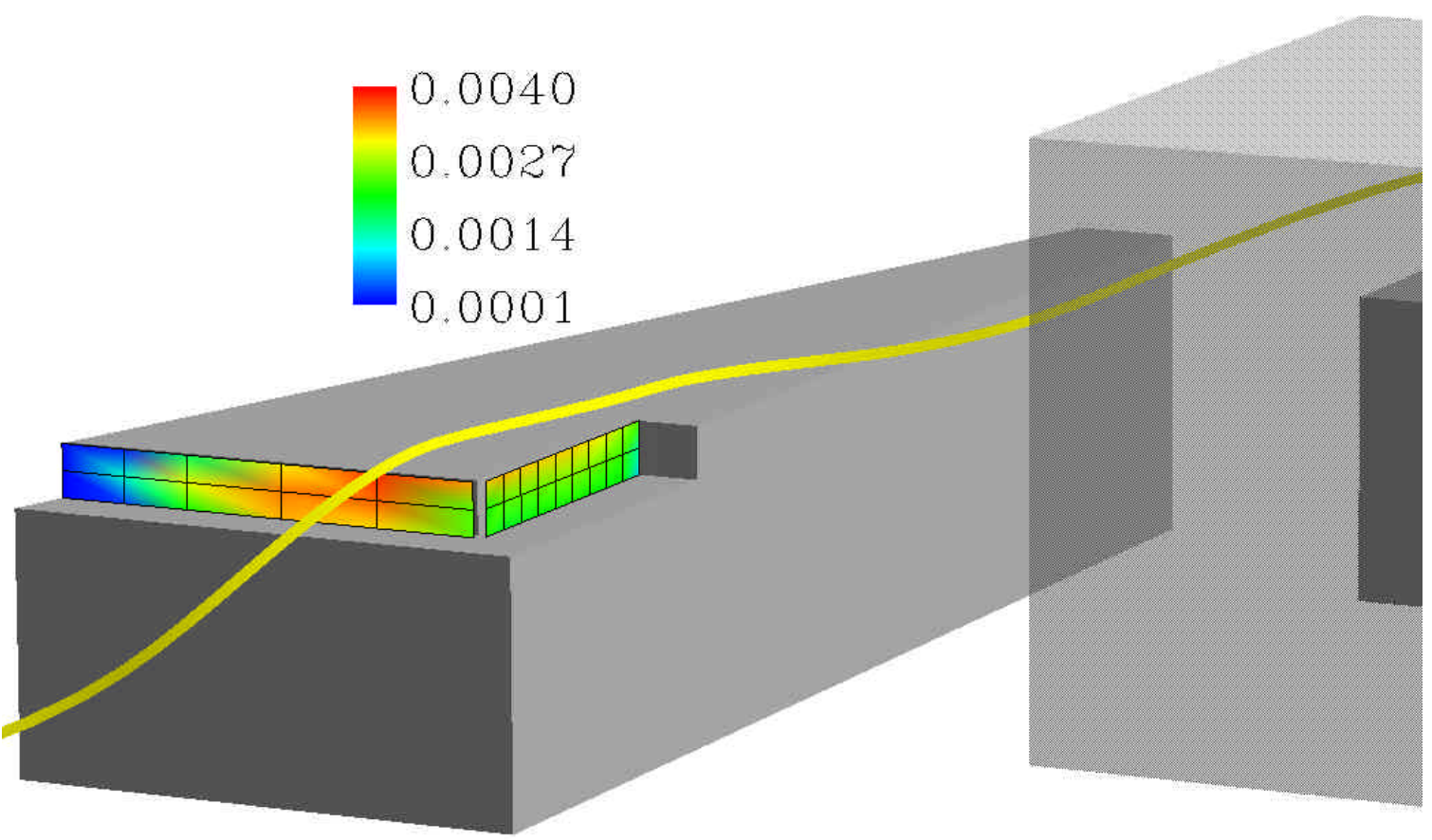

Figure 4: Kitchen exhaust stack reaching air intakes of the adjacent office building. The plume centerline is also illustrated. Exhaust enters the intake at an average of about 750 dilutions.

\section{CFD MODELING ON A LARGER SCALE}

As the domain of a project gets larger, the benefits of using CFD for odor study decreases. The fewer buildings in an area and the wider the domain being modeled, the less important the microscale wind elements becomes at determining downwind 
concentrations of odorous substances. For example, if dispersion modeling is needed to determine odor impact at a residential neighborhood a kilometer downwind of a large factory, then the most important microscale area of windflow is at the stack and source building. The stack tip downwash and building recirculation zones will have the most influence at determining the distribution of odor around the building. This distribution determines the distribution and concentration downwind at the sensitive receptors. The PRIME algorithm can adequately handle these elements of the problem.

The project discussed in this section is an odor study where the scale of the domain is sufficiently local that the proper model to use is not clear cut. In this example, occupants of a large two-story office/manufacturing building have complained about odor impacts from a nearby manufacturing facility that has two paint booths. Also, odors were noticeable in the parking lot between the buildings during the same periods.

The two paint booth stacks are located on the south side of the building. The detection threshold of the paint stack emissions was measured at $1300 \mathrm{~d} / \mathrm{t}$. The recognition threshold was at $800 \mathrm{~d} / \mathrm{t}$. The reports of odor in the impacted building always occurred during moderate to strong winds from the south. These winds place the plume from the two paint booth stacks directly upwind of the office building's main air intakes. The air handling units are located on the southeast corner of the office building in a mechanical penthouse on the roof. An overview of the site is provided in Figure 5.

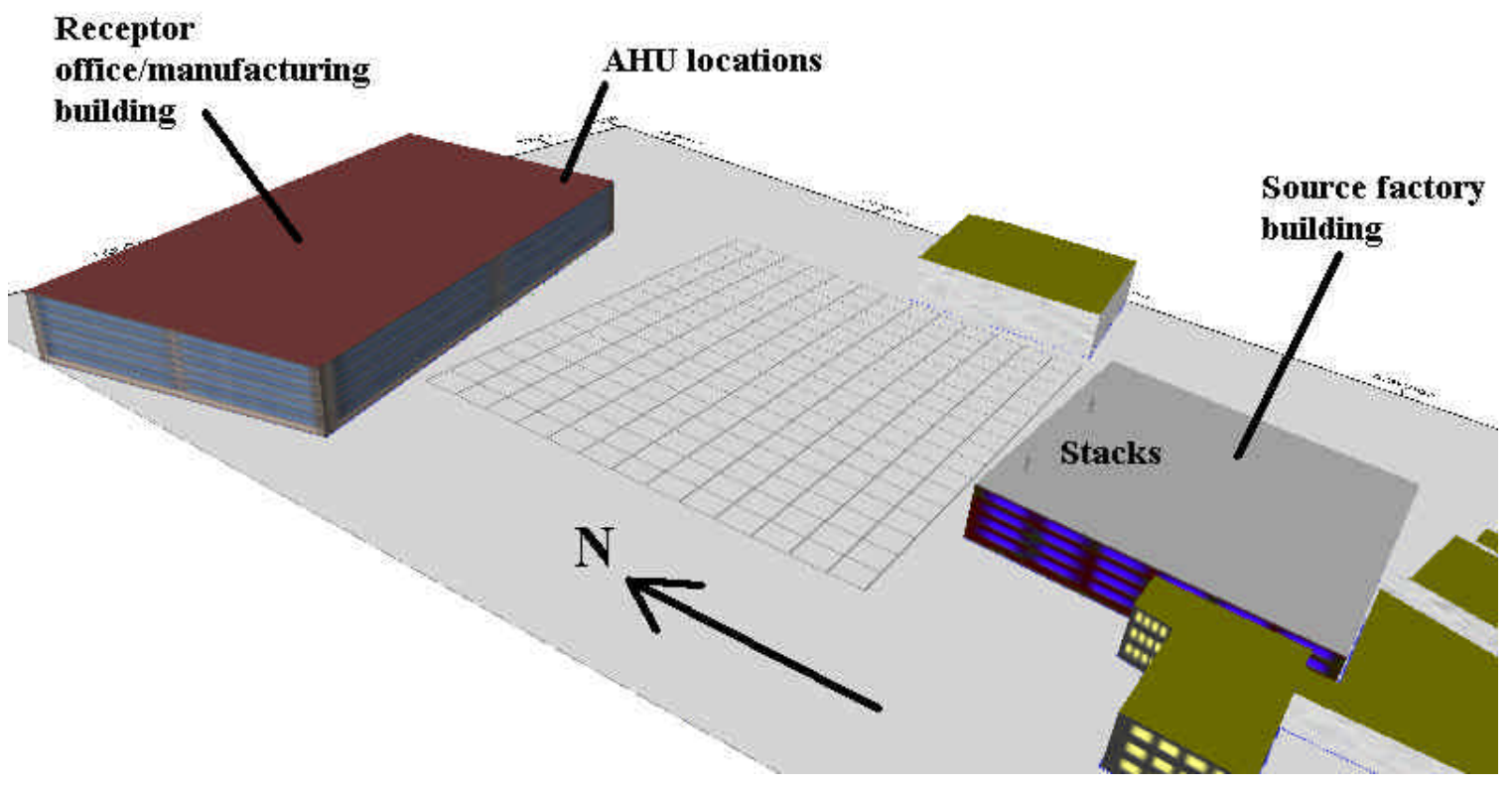

Figure 5: Overview of the odor study domain. The odor source factory is upwind of the office building during winds from the south. The two paint booth stacks are located on the north roof of the factory. The receptor office AHUs are located at the southeast corner of the office building. The grid at the surface between the two buildings is the receptor grid used for the ISC and Aermod modeling. Concentrations are measured at 1.5 meters above the ground in the parking lot and at the $\mathrm{AHU}$ location on the office building. 
Air dispersion modeling was conducted using CFD to analyze the current situation and to test alternatives. However, the local air agency had not previously seen CFD used for dispersion modeling and requested a comparison to results from ISCST3. AERMOD was also run to provide a comparison for this paper. Both models involved the use of the PRIME algorithm, which allows for the model to take into account the interaction of the plume with the building.

\section{Initial CFD Case}

Modeling was conducted using one meteorological case identified as a complaint period. This hour was also chosen due to its high wind speed, which often increases dilutions and reduces complaints by increasing the dispersal of the plume by turbulence and rapid downwind transport. A more extensive study would involve comparing impacts between the models with different wind speeds.

Ambient temperature and stack temperature were assumed to be equal, and atmospheric pressure was initialized at $1000 \mathrm{mb}$. Modeling was conducted in two parts. First, the wind fields were established with a run of six seconds of real time. This is the amount of time tests have shown is required to form a steady state solution with most wind speeds. With roughly 500,000 cells at a time step of 0.05 seconds, the run took roughly 5 hours to complete. After completion, the resulting windfield was visually inspected to assure the windfields were properly formed. Then the field is frozen, and the exhaust is released from the stack.

In this case, both paint booth stacks were modeled. Both stacks are square with fairly small flow rates. The east stack is the smaller of the two with an opening of $4 \mathrm{ft}^{2}$ and a flow rate of 3,000 cfm. The west stack has an opening of $8 \mathrm{ft}^{2}$ and a flow rate of 8,120 $\mathrm{cfm}$. Each stack is $10 \mathrm{ft}$ tall. Modeling was conducted using a unit emission (100\% odor at stack) to find the dilution of exhaust at various receptors. Number of dilutions at a point is calculated by $(1 /$ concentration -1$)$.

A benefit of CFD modeling is the complete three-dimensional visualization of the plume, as illustrated in Figure 6. The behavior of a plume and the areas hat it is most likely to impact can be easily seen in the visualization before any scalar values are measured. In this case, the plume dips a bit in the wake of the source building and rises as the air lifts to flow over the receptor building. A good portion of the plume comes very close to the roof of the source building. However, the majority of the plume remains above the roof, preventing the most serious impacts. The center of the plume at this point remains at about 150 dilutions, whereas impacts at the roof are much lower.

Concentrations of exhaust at the receptor building roof reach as high 625 dilutions, but the average for the roof near the air intakes is lower at 1,780 dilutions. Odors at the receptors in the parking lot were as high as 590 dilutions with an area average of around 750 dilutions. An illustration of the concentrations is available in Figure 7. 


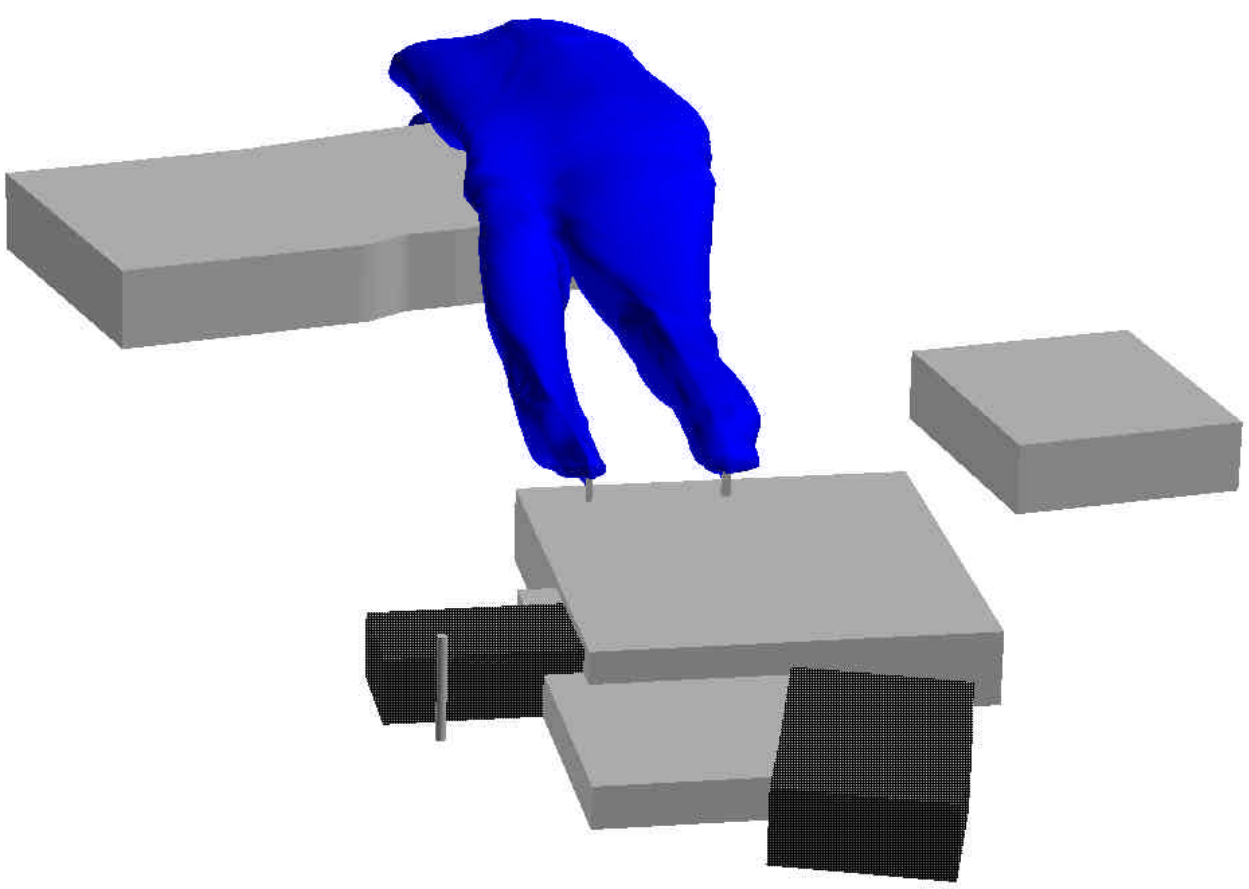

Figure 6. Three-dimensional illustration of plume generated by CFD model. Stacks are at $10 \mathrm{ft}$. The plume boundary is shown at 1,000 dilutions.

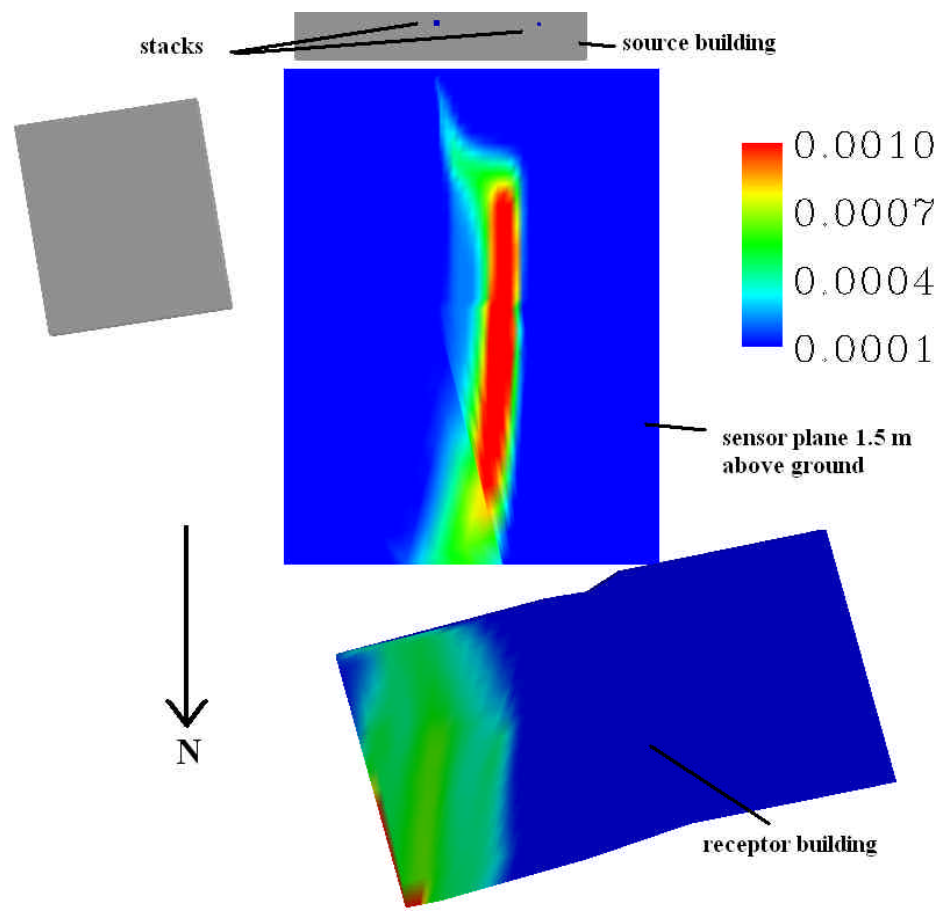

Figure 7: Illustration of visualization of concentrations as a scalar from CFD solution. Only a portion of the source building is shown. Stacks are at $10 \mathrm{ft}$. Concentrations are shown at the parking lot and on the roof of the office building. Scale is in concentration, which is inverse dilutions. 


\section{Alternative CFD Case}

Like ISCST3 and AERMOD, CFD models can be used to test alternative conditions. Building or stack parameters, shapes, and sizes can be altered to learn what combination will minimize concentrations at the receptors. In this case, the only real option was to raise the stack. However an overly high stack would have required expensive structural support. The task was to find the minimum additional height that would eliminate the impact on the neighboring building. Additional modeling was done with the stacks raised to 20 feet.

At 20 feet the odors in the parking lot area dropped to 20,000 dilutions. The odors at the roof of the office building dropped to 24,300 dilutions averaged over the area of the air handling units (AHUs). The results are illustrated in Figure 8. The reason for the dramatic reduction in the odors is discussed at the end of the paper.
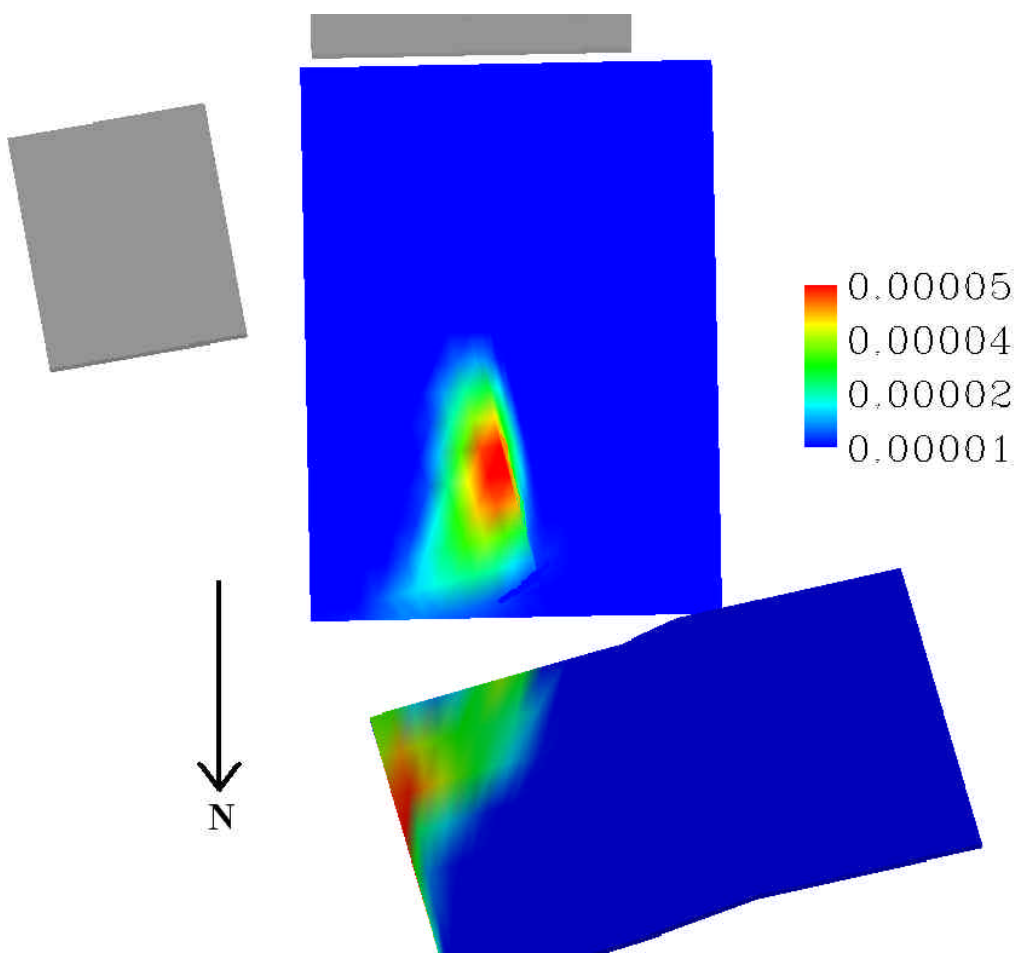

Figure 8: Odor concentrations at the parking lot and roof of the office building from CFD solution. Stacks are at $20 \mathrm{ft}$. Note that scale is in concentration and top of scale (red) is a factor of 20 lower than the scale in Figure 7.

\section{ISCST3 PRIME RESULTS}

ISCST3 was also used to model the $8 \mathrm{~m} / \mathrm{s}$ meteorological hour identified as a time of when strong odors were observed at the office building. Surface data and upper air data were available from a quite close by airport to create the meteorological inputs for the 
modeling. The model assumed complex terrain with elevated terrain entered as a way of putting the downwind building into the model. Receptors were located in the parking lot between the two buildings and on the rooftop of the impacted building. The parking lot receptors were set 1.5 meters above flat ground. The rooftop receptors were placed 1.5 meters on top of 10 meter high ground. Modeling was conducted using rural dispersion coefficients. Because the plume and receptors are lower than the initial stack height ISCST3 used the simple terrain lateral dispersion coefficients rather than the $22.5^{\circ}$ sector average. Odor emissions were set at a unit emission rate $\left(1 \mathrm{unit} / \mathrm{m}^{3}\right)$.

ISCST3 results varied from the CFD results both in the magnitude of the impact and the area of heaviest impact. As shown in Figure 9, with $10 \mathrm{ft}$. stacks the plume has a much lower impact in the parking lot between the source building and the office building but a higher impact on the building itself. The average concentration in the parking lot is about 1600 dilutions. The average roof impact around the AHU location was 910 dilutions.

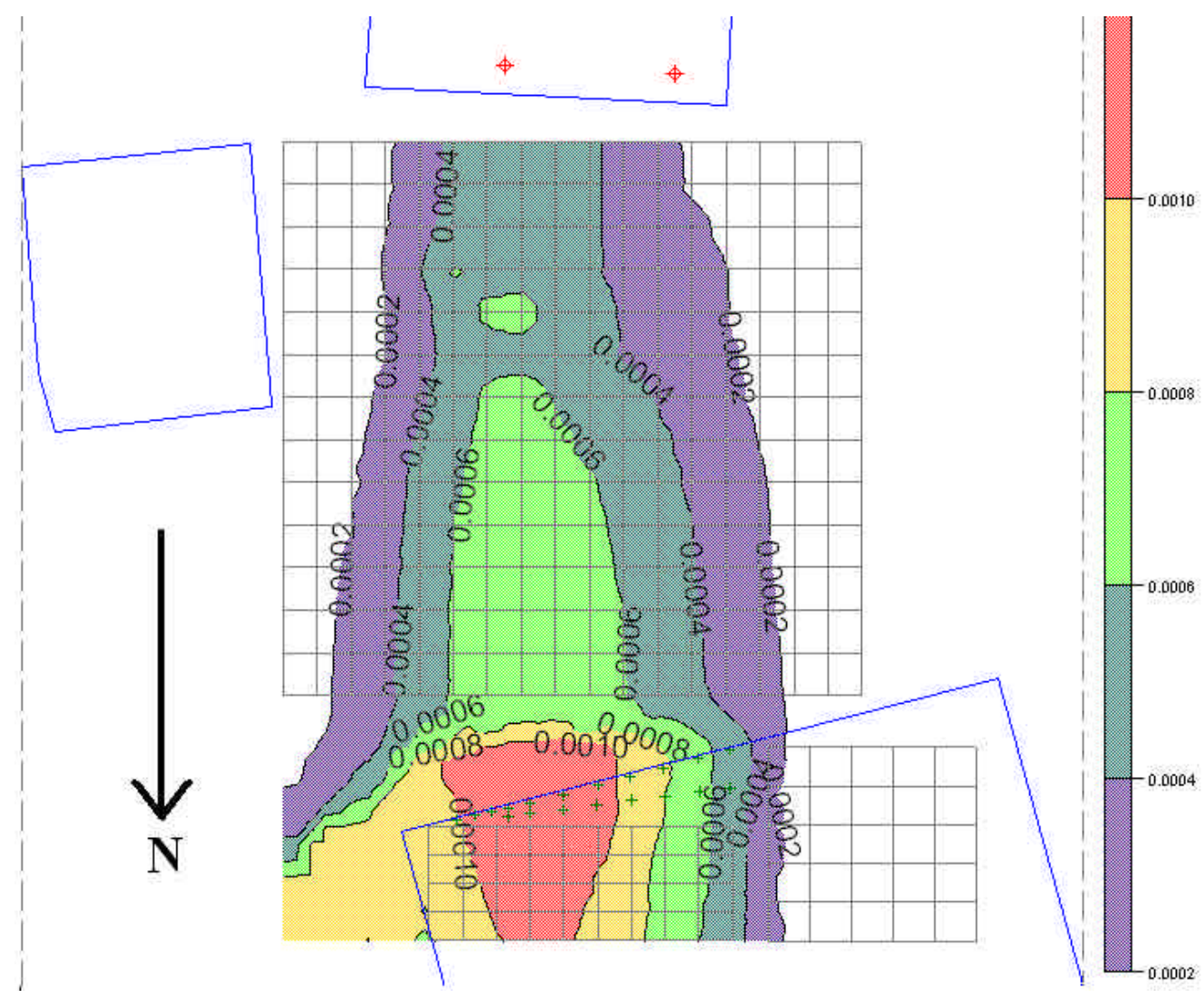

Figure 9: Results of ISCST3 modeling with $10 \mathrm{ft}$. stacks. The impacts are highest at the rooftop of the office building near the location of the air handling units. The two stacks are identified by crosshairs on the source building. Discrete receptors on the office building are identified by "+" and were placed to provide continuity over the building roof. 
Comparing these results to the CFD run, we notice that the ISCST3 model did not estimate concentrations at the parking lot as high as those given by the CFD model. A tongue of higher dilutions is present, indicating some emphasis on the lee recirculation zone of the source building. However, the odors in the parking lot are still much less than the 600 dilutions computed in the parking lot with CFD.

Another interesting difference is the east-west alignment of the higher concentration area in relation to the stacks. In the ISCST3 results the higher concentrations are directly downwind of the larger stack. In the CFD run, the higher concentrations are farther west, more between the two stacks and curving eastward as it approaches the office building. This is a good illustration of the power of the CFD within the building influence zones. CFD computes the flow of the wind field through the arrangement of buildings. Thus, this flow will veer different directions depending on the building arrangement, as illustrated in Figure 10.

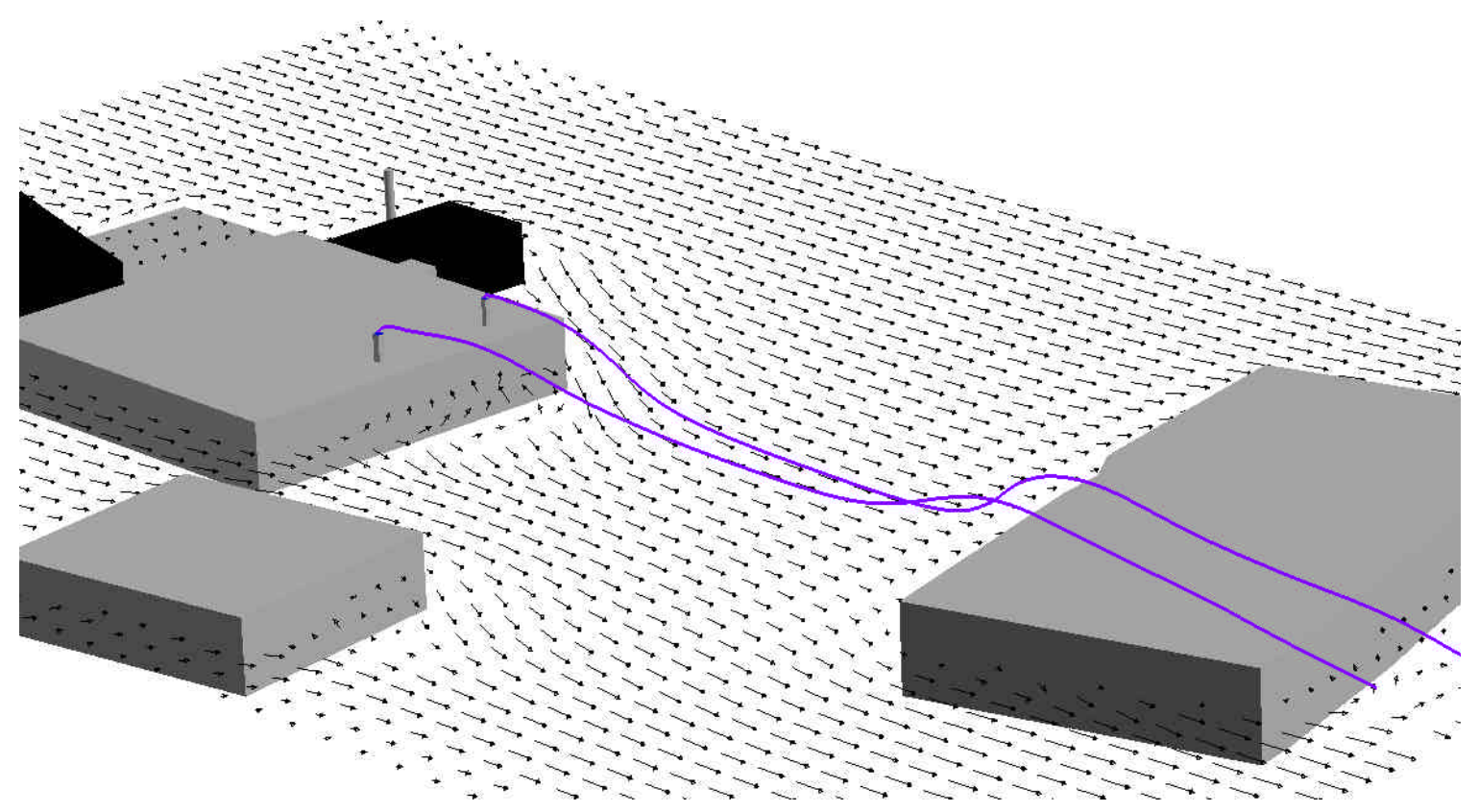

Figure 10: CFD modeling results with illustration of the wind vectors at 4 meters above the ground. The plume centerlines are also shown.

As also illustrated in Figure 10, the plume on the western most stack dips further towards the ground then the east stack, mostly due to its slower exit velocity. The plume is lower initially, so it is more influenced by the re-entrainment zone.

The ISCST3 results for the $20 \mathrm{ft}$. stacks were somewhat surprising. The odor concentrations did not change as significantly as they did in the CFD model for the higher stacks. In the ISCST3 results the model predicted the highest odors again at roof level at 900 dilutions. While this is marginally lower than the 850 maximum dilutions predicted with 10 foot stacks, it is still of the same magnitude. ISCST3 results for 20-ft. 
stacks are shown in Figure 11. The most noticeable change is in the concentrations at the parking lot. Concentrations that were as high as 1,600 dilutions in the ISCST3 model with 10-ft. stacks are now at around 2,200 dilutions in the same regions.

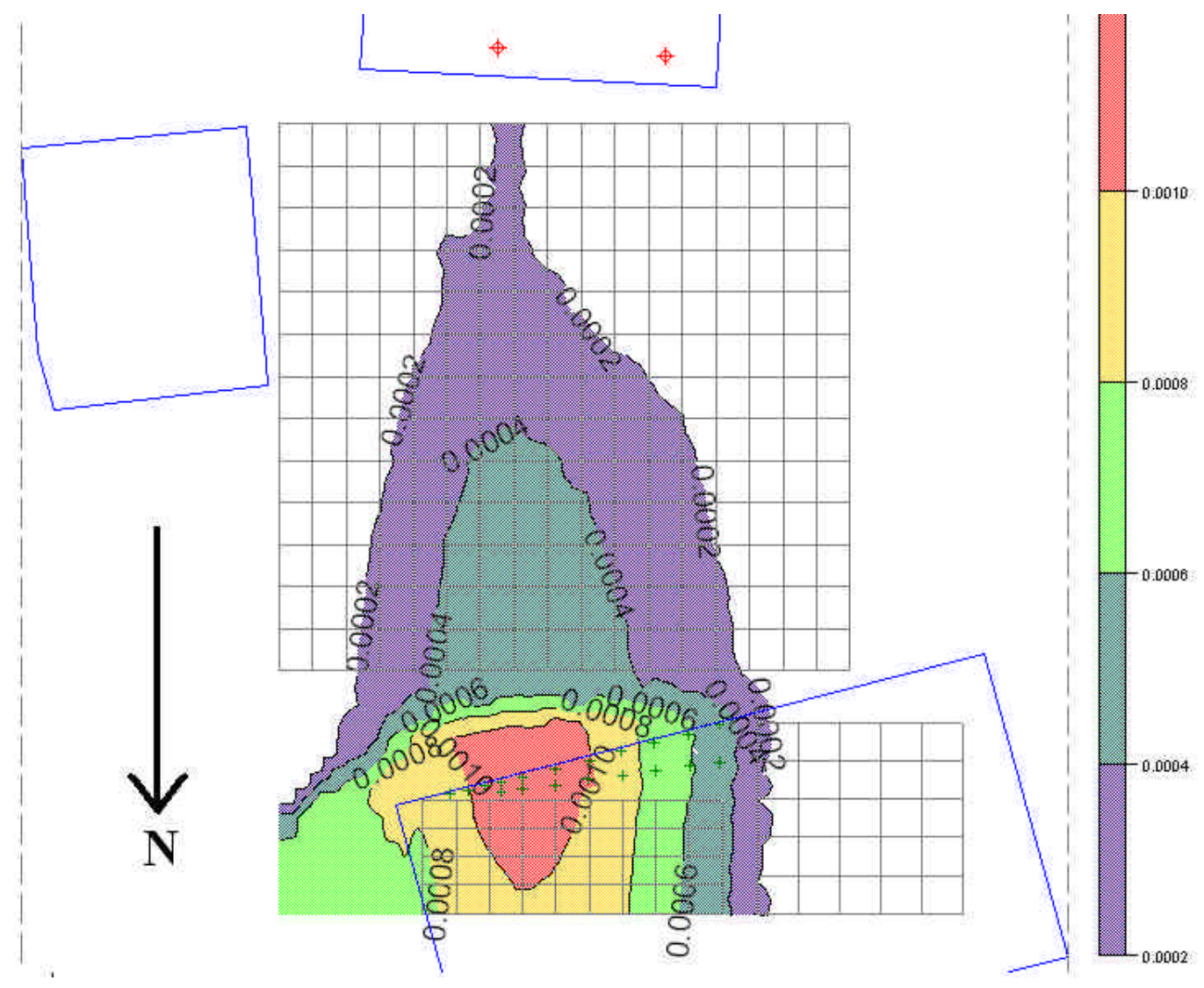

Figure 11: ISCST3 results with 20-ft stacks. The concentration pattern and magnitude at the roof are similar to the $10-\mathrm{ft}$ case. Concentrations at the parking lot are lower.

Note that the scale in this figure and in Figure 9 is the same.

\section{AERMOD PRIME RESULTS}

An AERMOD meteorological file was built using the same data sources as used for the ISCST3 model and assumed summer conditions for the ground characteristics variables. The terrain file was constructed from the local digital elevation data files although it was necessary to use a work around to get it to read the office building as terrain.

The AERMOD results are more like the CFD results in the distribution of the highest concentrations. However, the dilution levels are far below that of the CFD model. The highest concentrations were measured in the parking lot, in the same region as the CFD model. However, the number of dilutions of the exhaust was much higher in the 
AERMOD results, at 2,000 dilutions. Odors at the roof of the office building were predicted at about 2,860 dilutions with a high of 2,500 dilutions. The concentrations are illustrated in Figure 12.

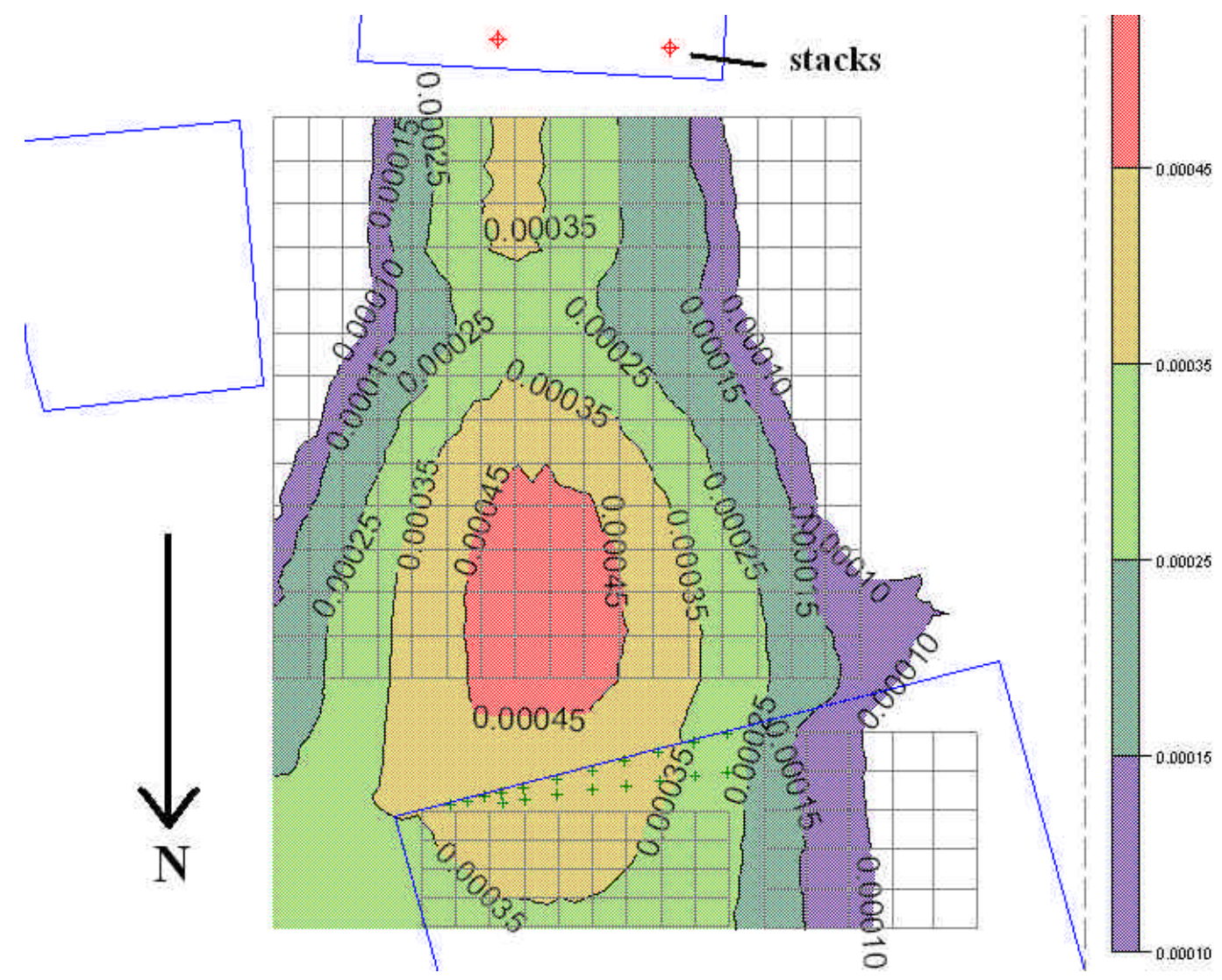

Figure 12: Illustration of AERMOD results for $10 \mathrm{ft}$. stacks. Like CFD, the highest concentrations are in the parking lot at about the same distance from the source building. However, the magnitude of impacts is lower. Note that the scale maximum is 2.2 times smaller than the scale in Figure 11.

As with the ISCST3 modeling, the alignment of the plume is more east than the CFD results, being directly downwind of the larger stack. Also, the parking lot high impact zone is a bit farther north than the highest impact region in the CFD modeling. Overall though, the concentrations predicted by AERMOD seem to be lower than experience suggests occurs in these conditions.

As with the ISCST3 results, the AERMOD results using 20-ft. stacks were similar in magnitude to the 10- $\mathrm{ft}$. stack runs, as seen in Figure 13. Maximum concentrations at the office building roof were around 3,030 dilutions compared to 2,000 dilutions with 10-ft stack. However, the distribution of impacts is much different in the 20-ft run. The highest impacts now are estimated to be on the south roof of the office building, where as before they were located in the parking lot area. 


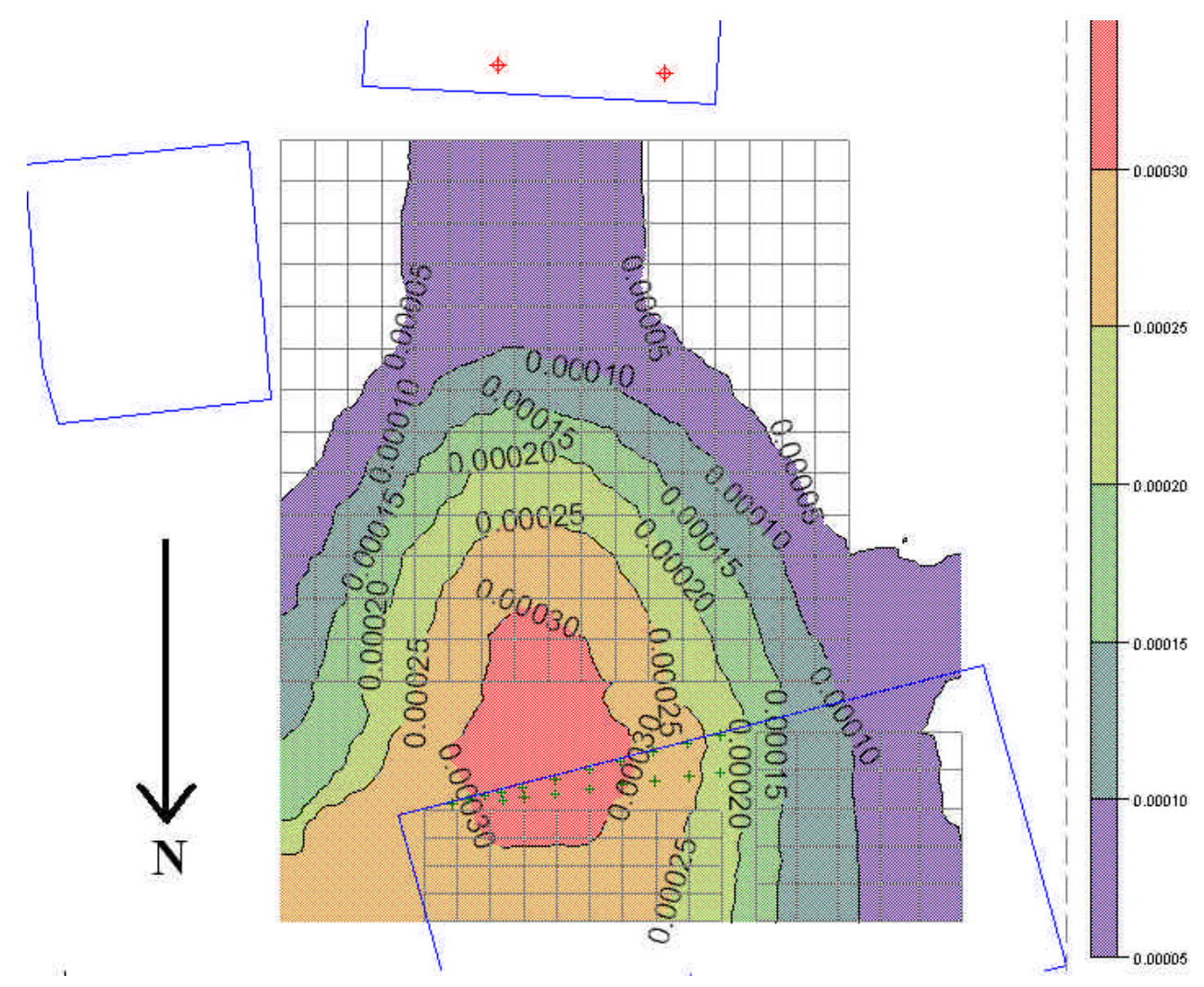

Figure 13: AERMOD concentration results with 20-ft stacks. Note that the scale maximum is 1.5 times lower than Figure 12 and 3.3 times lower than Figure 11.

\section{DISCUSSION}

The differences among the CFD, ISCST3 and AERMOD results are primarily related to the way they each treat the downwash behind the source building and the recirculation zone on the top of the office building. Looking back to Figure 10 the path the CFD plume centerline traces shows a strong drop in the lee of the source building and a "jump" at the leading edge of the office building. The jump can also be seen in the plume illustration graphic of the 20-ft. stack case in Figure 14. The recirculation zone that is the source of the jump up above the roof of the office building can be seen clearly in the wind vectors of Figure 15. Such a recirculation zone forcing a plume centerline upward more than the physical terrain itself simply is not part of the algorithms in ISCST3 or AERMOD.

In this case the recirculation zone at the leading edge of the downwind building is important to the impact on the AHUs on its roof. With the $10 \mathrm{ft}$. stack the plume enters the recirculation zone and mixes with it, distributing the odor onto the roof. With the $20 \mathrm{ft}$. stack the plume is carried up by the leading edge of the recirculation zone and avoids the roof top altogether. This is seen in the extreme change in the estimated dilution level at the roof in the two cases. The predicted success of the $20 \mathrm{ft}$. stack has been confirmed in 
practice. Since the installation of the taller stack there have been no complaints at the office building, including wind conditions when there were complaints in the past.

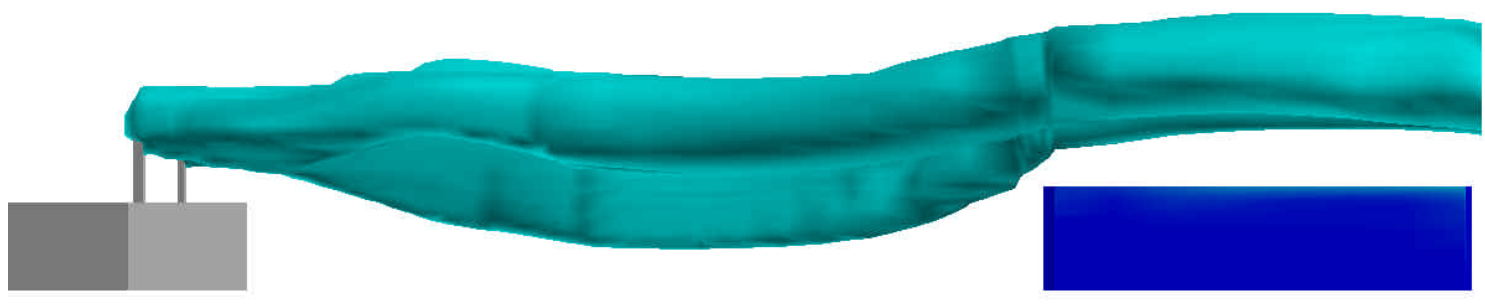

Figure 14: Plume outline at 1,000 dilutions with 20-foot stacks.

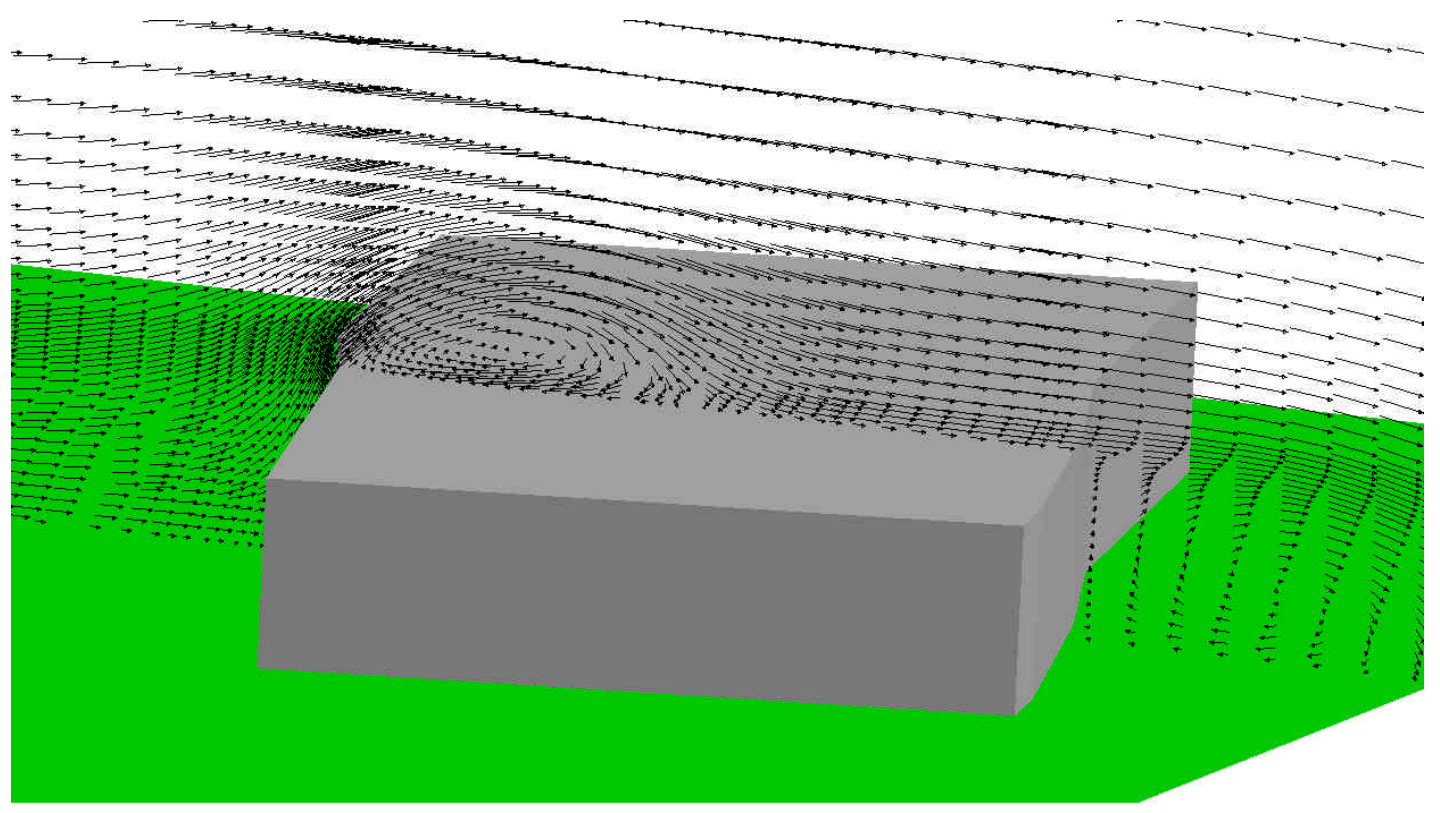

Figure 15. Wind vectors on an $\mathrm{x}-\mathrm{z}$ plane through the modeling domain illustrating the recirculation zones on the top and in the lee of the office building. The updraft at the leading edge of the building accounts for the "jump" in the plume seen in Figure 14.

This comparison of the three models also gives us an opportunity to compare the potential validity of each approach. We know that during the meteorological situation modeled, before the installation of the $20 \mathrm{ft}$. stack, that there were complaints both from the office building and in the parking lot, with the observation that the odor was stronger in the parking lot. Thus the average odor strength at both locations must have exceeded the odor detection threshold of $1,300 \mathrm{~d} / \mathrm{t}$ and quite probably the recognition threshold of $800 \mathrm{~d} / \mathrm{t}$. 
Table I lists the predicted dilutions of the plume from its original strength for an hour average at the AHUs on the roof of the office building and in the parking lot between the two buildings. Also shown in Table I are the adjusted predictions of dilutions for a shortterm gust or coherent plume segment, obtained by dividing by the 1.4 scaling factor discussed above. With both the CFD and AERMOD adjusted results at the AHUs at greater dilutions than the recognition threshold (the more likely odor strength when complaints would begin to be registered), either these two models are underestimating the odor strength at the AHU or complaints are coming from a very sensitive portion of the population. Both AEROMOD and ISCST3, but not the CFD model, significantly understate the odor strength at the parking lot.

Table I. Predicted Odor Strength from Three Models

\begin{tabular}{|l|c|c|c|c|}
\cline { 2 - 5 } \multicolumn{1}{c|}{} & \multicolumn{2}{c|}{ Office Building AHUs (d/t) } & \multicolumn{2}{c|}{ Parking lot (d/t) } \\
\cline { 2 - 5 } \multicolumn{1}{c|}{} & Modeled & Adjusted & Modeled & Adjusted \\
\hline CFD & 1800 & 1300 & 600 & 400 \\
\hline ISCST3 & 900 & 650 & 1600 & 1150 \\
\hline AERMOD & 2900 & 2000 & 2000 & 1400 \\
\hline
\end{tabular}

\section{CONCLUSION}

Today's building owners and residents need solutions to prevent avoid odors in offices and residences. CFD has an important role to play in modeling odors around buildings and other structures which conventional meteorological dispersion models are not designed to handle. It can be a powerful tool at the micro-scale level of the urban environment. It offers the opportunity to try alternative designs while a building is still in design to avoid serious problems that could be very expensive to correct later.

At a larger scale, the benefit of using CFD over standard EPA dispersion models breaks down. However, where the influence of buildings and obstacles to the airflow is significant, the EPA models have limited skill due to the complexity of airflow around sets of buildings. CFD is an effective solution in these cases at a medium scale, especially when the sensitive receptor is located on or is part of a building. It may be effective at a larger scale where unusual topography or buildings make an important contribution.

The most important benefit of CFD may be in providing a physical understanding of the results during evaluation of alternative design solutions. In the stack extension review of the manufacturing facility provided here, the clear physics of the results made it easy to accept the evidence of the CFD model for the solution offered by a $20 \mathrm{ft}$. stack rather than the results from ISCST3, which would have dictated a much higher stack.

In this study, the results of three models, CFD, AERMOD, and ISC were compared for the manufacturing facility project. The results varied among the models qualitatively and quantitatively. CFD demonstrated the most promise for modeling alternatives because it 
provides the opportunity to examine the results more completely. Of the three models, CFD provided more balanced results at all receptors. However the comparison does not result in a clear endorsement of any one of the three models.

In order for CFD to be widely relied on for analyses of this type it will be important to evaluate the various assumptions that are built into the CFD model and to understand their individual and cumulative effect on the results. True validation of the CFD model will require extensive comparisons of the CFD results with measured values at various receptors around a building. This work is ongoing and will lead to improved modeling of urban microenvironments.

\section{ACKNOWLEDGEMENTS}

The authors wish to acknowledge the substantial assistance they have received from Kevin O'Rourke and Adaptive Research, the producers of CFD 2000.

\section{REFERENCES}

Turner, D. Bruce (1970) Workbook of Atmospheric Dispersion Estimates; AP-26; U.S. Environmental Protection Agency; Research Triangle Park, N Carolina

Thompson, Rhonda (2000) Preliminary Analysis of 5-Minute Maximum Ambient $\mathrm{SO}_{2}$ Concentrations; unpublished report available at www.epa.gov/ttnamti1/files/ ambient/so2/techrept.pdf (10/23/03) 